\title{
Myeloproliferative neoplasms: From JAK2 mutations discovery to JAK2 inhibitor therapies
}

\author{
Francesco Passamonti ${ }^{1}$, Margherita Maffioli' ${ }^{1}$, Domenica Caramazza ${ }^{1}$, Mario \\ Cazzola ${ }^{2}$ \\ ${ }^{1}$ Division of Hematology, Department of Internal Medicine, Ospedale di Circolo e Fondazione Macchi, Varese, Italy \\ 2 Division of Hematology, Department of Oncology and Hematology, Fondazione IRCCS Policlinico San Matteo, University of \\ Pavia, Italy \\ Correspondence to: Francesco Passamonti, email: francesco.passamonti@ospedale.varese.it
}

Keywords: myelofibrosis, polycythemia, thrombocythemia, JAK2

Received: May 30, 2011 ,

Accepted: June 1, 2011,

Published: June 5, 2011

Copyright: () Passamonti et al. This is an open-access article distributed under the terms of the Creative Commons Attribution License, which permits unrestricted use, distribution, and reproduction in any medium, provided the original author and source are credited.

ABSTRACT:

\begin{abstract}
Most BCR-ABL1-negative myeloproliferative neoplasms (MPN) carry an activating JAK2 mutation. Approximately $96 \%$ of patients with polycythemia vera (PV) harbors the V617F mutation in JAK2 exon 14, whereas the minority of JAK2 (V617F)negative subjects shows several mutations in exon 12. Other mutation events as MPL, TET2, LNK, EZH2 have been described in chronic phase, while NF1, IDH1, IDH2, ASX1, CBL and Ikaros in blast phase of MPN. The specific pathogenic implication of these mutations is under investigation, but they may have a role in refinement of diagnostic criteria and in development of new prognostic models. Several trials with targeted therapy (JAK inhibitors) are ongoing mostly involving patients with PMF, post-PV MF and post-essential thrombocythemia (ET) MF. Treatment with ruxolitinib and TG101348 has shown clinically significant benefits, particularly in improvement of splenomegaly and constitutional symptoms in MF patients. On the other hand, JAK inhibitors have not thus far shown disease-modifying activity therefore any other deduction on these new drugs seems premature.
\end{abstract}

Chronic myeloproliferative neoplasms (MPN) include three main diseases that are polycythemia vera (PV), essential thrombocythemia (ET) and primary myelofibrosis (PMF) [1].

As illustrated in Figure 1, ET patients may slowly progress to PV, especially those carrying the JAK2 (V617F) mutation [2, 3]. Furthermore, PV and ET have a variable risk of transformation to secondary myelofibrosis (post-PV and post-ET MF) [4, 5] and subsequently to acute myeloid leukemia (AML) [6]. Finally, AML may occur directly from ET and PV without the intermediate step of MF, in which case AML may lack $J A K 2$ mutation even if arising from JAK2-positive MPN [7]. Evolution to post-PV and post-ET myelofibrosis occurs at a rate of $10 \%$ to $20 \%$ after 15 to 20 years of follow-up [5]. Progression to AML is less frequent in PV and ET (2-7\%) than in PMF $(8-30 \%)[2,8-10]$.
TOWARDS

\section{UNDERSTANDING OF MPN}

The as yet unfinished story of MPN pathogenesis started with the discovery of the JAK2 (V617F) mutation;[11] afterwards many other mutations have been found in chronic (exon 12 mutations of $J A K 2, M P L$, TET2, LNK, EZH2) and blast phase (NF1, IDH1, IDH2, $A S X L 1, C B L$, Ikaros ) of MPN, some involving JAKSTAT signaling activation, others chromatin remodeling and others leukemic transformation. Mutations with a gain of function of $J A K 2, M P L, C B L$ and those with a loss of function of $L N K$ and $N F 1$ activate the JAKSTAT pathway[12] leading to a final phenotype of MPN with alteration of immune response, inflammation, angiogenesis, proliferation and resistance to apoptosis (Figure 2). This pathway is the target of new JAK2 inhibitors. 


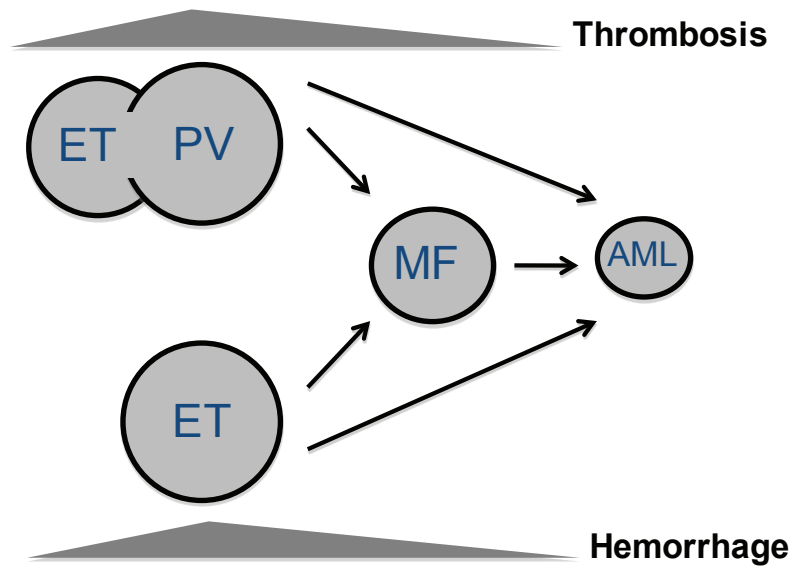

Figure 1: Natural history of myeloproliferative neoplasms. Most frequent clinical complications in MPN patients are thrombosis, whereas hemorrhage is above all observed in essential thrombocythemia (ET) patients. ET may slowly develop into polycythemia vera (PV), especially if it carries the JAK2 (V617F) mutation. PV and ET may progress to myelofibrosis (post-ET, post-PV MF) and then turn into acute myeloid leukemia (AML), although they may evolve into AML even without showing a MF phase.

\section{Mutations mainly found during chronic phase of MPN}

\section{JAK2 (V617F)}

$J A K 2$ (V617F) mutation (Janus kinase 2), occurring within exon 14 of JAK2 and located on 9p24 is the most frequent mutation in MPN, ranging from roughly $96 \%$ in PV to $65 \%$ in ET and PMF.[11, 13] This mutation affects the auto-inhibitory domain ( $\mathrm{JH} 2$, pseudokinase) of JAK2 leading to constitutive activation of $J A K 2$ and JAK/STAT signaling. In retroviral mouse models $J A K 2$ (V617F) confers a PV-like phenotype with a final evolution to MF,[14] whereas when modulating allele burden, lower mutant load generates thrombocythemia and higher mutant burden results in polycythemia [15]. This means that an increased signaling through JAK2 (V617F) may be responsible for a PV phenotype, as demonstrated in patients [13]. Clinical phenotype does not depend only on allele burden, in fact, downstream of JAK2, an enhanced phosphorylation of STAT1 or STAT5 may promote megakaryopoiesis or erythropoiesis [16].

\section{JAK2 exon 12 mutations}

$J A K 2$ exon 12 mutations have been described in JAK2 (V617F)-negative PV and cover less than 2\% of PV diagnoses [17]. Seventeen different mutations have been described with N542-E543del, K539L, and E543-D544del as the most frequent ones [18]. Exon 12 mutations result in strong ligand-independent signaling through JAK2 as demonstrated by the high levels of phospho-JAK2 and also of phospho-ERK1 and phospho-ERK2 [17],

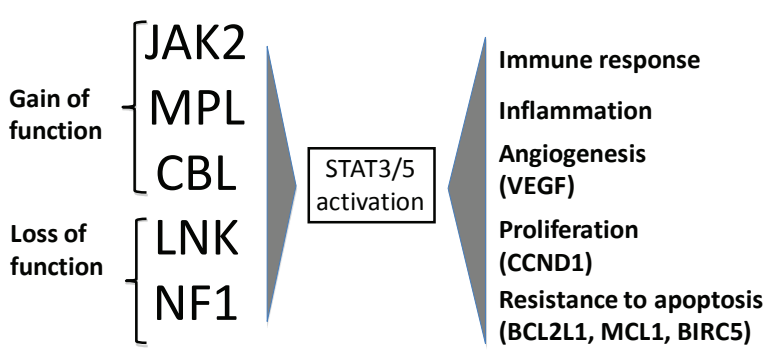

Figure 2: MPN mutations activating STAT3/5. Mutations of $J A K 2, M P L$ and $C B L$ (due to gain of function) and mutations of $L N K$ and $N F 1$ (due to loss of function) activate STAT3/5 which, through nuclear signal transduction, determines an amplification of immune response, inflammation, angiogenesis and proliferation, mostly modulated by higher circulating cytokines levels. STAT3/5 activation also confers resistance to apoptosis which promotes and supports myeloid precursor proliferation.

highlighting the cross talking with the Ras-ERK signaling pathway. Compared with JAK2 (V617F)-positive PV patients, those with exon 12 mutations had significantly higher hemoglobin level and lower platelet and leukocyte counts at diagnosis but similar incidences of thrombosis, myelofibrosis, leukemia, and death [18].

\section{MPL mutations}

The MPL (myeloproliferative leukemia virus) gene, located on $1 \mathrm{p} 34$, can comprise different mutations within exon 10 targeting the transmembrane domain of MPL receptor [19]. The parent of these mutations is the W515L, resulting in constitutive activation of the JAK/ STAT pathway. Mutation frequency is estimated at 3-5\% for ET and $8-10 \%$ for PMF.[20, 21] In W515L-murine models, the mutation confers a PMF-like phenotype with thrombocytosis, splenomegaly, and fibrosis. In some instances $M P L$ mutations and JAK2 (V617F) coexist as two independent clones or two subclones [20], revealing the genetic complexity of MPN.

\section{TET2 mutations}

TET2 (ten eleven translocation), a putative tumor suppressor gene located on 4q24, can be affected by an array of frameshift, nonsense and missense mutations [22, 23]. Experiments with NOD-SCID mice suggest that TET2 might be involved in self-renewal pathways relevant to hematopoietic transformation [23]. Hierarchically, TET2 mutations occur before or after the acquisition of JAK2 mutations or may be an independent event [24]. In a large cohort of MPN patients, TET2 mutations were detected in $16 \%$ of $\mathrm{PV}, 5 \%$ of ET, $17 \%$ of PMF, $14 \%$ of post-PV MF, $14 \%$ of post-ET MF and $17 \%$ of blast phase MPN; but TET2 mutations are also described in other myeloid malignancies such as myelodisplastic syndromes (MDS), MPN/MDS syndromes and acute myeloid leukemia with variable, although not unequivocally defined, prognostic impact. 


\section{LNK mutations}

$L N K$, located on 12q24.12, encodes for LNK, a plasma membrane-adaptor protein whose functions include inhibition of wild type and mutant JAK2 signaling [25]. In fact, LNK is a negative regulator of thrombopoietin-mediated JAK2 activation. It's intriguing that LNK-deficient mice exhibit increased number of megakaryocytes and erythrocyte progenitors, as well as an expanded hematopoietic stem cell pool with enhanced self renewal [26]. Loss of function mutations of LNK situated within exon 2 have been described at low frequency in ET and PMF, and in erythrocytosis with low erythropoietin $[27,28]$.

\section{EZH2 mutations}

Enhancer of zeste homolog 2 (EZH2) located on $7 \mathrm{q} 36.1$ encodes the catalytic subunit of the polycomb repressive complex 2 (PRC2), a highly conserved histone H3 lysine 27 methyltransferase that influences stem cell renewal by epigenetic repression of genes involved in apoptosis [29]. EZH2 has oncogenic activity. Different mutations have been found in patients with myeloid malignancies with a mutation frequency of $12 \%$ in MDS/ MPN and of $13 \%$ in MF [29].

\section{Mutations mainly found outside chronic phase of MPN}

\section{NF1 mutations}

NF1 (neurofibromatosis-1) (17q11.2) is associated with the hereditary von Recklinghausen's neurofibromatosis. It has been shown that these patients have an increased risk of developing various tumors including myeloid leukemia [30]. NF1 functions as a negative regulator of the RAS signal transduction pathway, cross-talking with the JAK-STAT pathway, and loss of NF1 can lead to a progressive myeloproliferative disorder. NF1 mutations were described in few patients with post-ET and post-PV MF, while no patients with chronic phase MPN carried these mutations [31].

\section{IDH1 and IDH2 mutations}

Isocitrate Dehydrogenase 1 and 2 (IDH 1 and IDH2) are located at $2 \mathrm{q} 33.3$ and $15 \mathrm{q} 26.1$, respectively.[32] IDH1 mutated protein produces 2-hydroxyglutarate (2-HG). Although the role of 2-HG in tumor initiation and growth is not fully understood, this putatively oncogenic metabolite plays a role in MPN progression to leukemia besides the well defined role in the pathogenesis of gliomas [33].The frequency of these mutation in chronic MPN such as PV, ET and PMF is under 5\%, but it becomes $21 \%$ in postMPN AML [34].

\section{ASXL1 mutations}

ASXL1 (Additional Sex Combs-like 1) is located on $20 \mathrm{q} 11.1$ and belongs to a family of three identified members that encode poorly characterized proteins regulating chromatin remodeling, enhancing transcription of certain genes while repressing the transcription of others.[35] Mutations, mainly frameshift and nonsense, occur within exon 12. Both TET2 and ASXL1 alterations lead to an increase in the program of self-renewal in MPN progenitors through modifications of DNA and histone regulation. Mutations within ASXL1 are found in $8 \%$ of MPN, $11 \%$ of MDS, $43 \%$ of chronic myelomonocytic leukemia, $7 \%$ of de novo AML, and $47 \%$ of secondary AML [35].

\section{CBL mutations}

The casitas B-lineage lymphoma (c-CBL) gene is located on 11q23.3. CBL is a well characterized protein that plays both negative and positive regulatory roles in tyrosine kinase signalling.[36, 37] CBL targets a variety of activated tyrosine kinases for degradation and may also serve as an adaptor by recruiting some downstream transduction components. Mutations in this gene are more frequent in juvenile myelomonocytic leukemia (17\%) than in MPN (6\% in PMF) [38].

\section{IKAROS mutation}

The transcription factor Ikaros encoded by the IKZFI gene $(7 \mathrm{p} 12)$ has a role in the regulation of hematopoiesis. In murine models, deficiency of Ikaros function may induce lymphoproliferative disorders and B- and T-cell leukemia, but also anemia and thrombocytopenia. In MPN, hemizygous loss of IKZF1 was detected in $21 \%$ of post-MPN leukemia and in $0.2 \%$ of chronic phase MPN indicating oncogeneic properties of IKAROS defects [39]. Post-MPN AML involving Ikaros may be due to the genetic instability after Ikaros deletion or, alternatively, by the recently documented interaction of Ikaros with the JAK-STAT pathway.

\section{TOWARDS NEW TARGETED THERAPIES}

Many drugs are now under investigations targeting different pathways critical for MPN development, such as the JAK-STAT (JAK2-inhibitors: INCB018424, TG101348, CEP701, CYT387, SB1518, AZD1480, XL019, LY2784544), the mTOR (everolimus), the MAPK (erlotinib), and the NF-Kb (bortezomib) pathways, or act through remodeling chromatin with a key role in epigenetics (givinostat, panobinostat, vorinostat). For a best update on new trials, we advise to check www. clinicaltrials.gov.

Most of JAK2 inhibitors are small molecules that act by competing with ATP for the ATP-binding catalytic site in the kinase domain. Preclinical studies have demonstrated activity of these drugs by direct inhibition of interleukin-6 signaling and of proliferation of JAK2(V617F)-positive $\mathrm{Ba} / \mathrm{F} 3$ cells $[40,41]$. In mouse models of JAK2 (V617F)- 
MPN, JAK2 inhibitors markedly reduced splenomegaly and preferentially eliminated neoplastic cells, resulting in significantly prolonged survival of mice. While treatment with a JAK2 kinase inhibitor ameliorates the MPN phenotype, it does not eliminate the disease-initiating clone [42].

Taking together all available clinical data on MPN, one may conclude that JAK2 inhibitors give a benefit to patients with MF, by reducing spleen size of $\sim 50 \%$ in approximately $40-50 \%$ of patients and by abolishing symptoms in the vast majority of MF patients. However, effect on these disease manifestations should be balanced with the safety profile. Anemia and thrombocytopenia are on-target toxicities expected with all JAK2 inhibitors. Other toxicities may involve non-JAK2 targets, as in case of gastrointestinal events during therapy with JAK2 inhibitors with off-target activity against FLT3 (CEP 701, TG101348, SB1518). For the current paper, we decided to report only data from the most promising JAK2 inhibitors, such as INCB018424 and TG101348, whose results are already available as full paper.

\section{INCB18424, Ruxolitinib}

A phase I/II trial with ruxolitinib (JAK1, JAK2 inhibitor, orally bioavailable) was conducted in 152 patients with PMF or post-PV/post-ET MF [40]. Eligible subjects were therapy-requiring patients, refractory, relapsed, intolerant to previous therapy, or patients with intermediate or high-risk Lille score, if at diagnosis. Main exclusion criteria were thrombocytopenia (platelets $<100$ $\mathrm{x} 10^{9} / \mathrm{L}$ ) and neutropenia (ANC $\left.<1500 \times 10^{9} / \mathrm{L}\right)$. The results available to date can be summarized in the following points. First, $15 \mathrm{mg}$ BID (10 mg BID if platelet count $<100 \times 10^{9} / \mathrm{L}$ ) was the best starting dose. Second, applying IWG-MRT criteria, $44 \%$ of patients obtained a clinical improvement (CI) of spleen size $(\geq 50 \%$ reduction from baseline) by palpation at 3 months and responses were maintained at 12 months in more than $70 \%$ of patients. The majority of patients had $\geq 50 \%$ improvement in constitutional symptoms due to the activity against proinflammatory cytokines. Among red blood cell (RBC) transfusion-dependent patients, $14 \%$ become RBC transfusion-independent. Third, no differences were reported in term of response rates according to disease type (primary or secondary MF) or JAK2 (V617F) mutational status. Fourth, non-hematologic toxicity occurred in less than $6 \%$ of patients and was usually grade 2 . At a dose of $15 \mathrm{mg}$ BID, grade 3 thrombocytopenia occurred in $3 \%$ of patients and new onset of anemia in $8 \%$ of $\mathrm{RBC}$ transfusion-independent patients. Thrombocytopenia was more frequent if platelet count $<200 \times 10^{9} / \mathrm{L}$ at treatment start; however, this toxicity proved to be reversible.

Two randomized trials with ruxolitinib are ongoing in MF patients: COMFORT I, randomizing ruxolitinib versus placebo, and COMFORT II, randomizing ruxolitinib versus best available therapy. The primary endpoint was the number of subjects achieving $\geq 35 \%$ reduction in spleen volume from baseline to week 24 for COMFORT I and the number of subjects achieving $\geq 35 \%$ reduction in spleen volume from baseline to week 48 for COMFORT II. Media release has recently revealed that both trials have met the primary endpoint.

\section{TG101348, SAR302503}

A phase I trial with TG101348 (JAK2 inhibitor, orally bioavailable) was conducted in 59 patients with PMF or post-PV, post-ET MF [41]. Eligible subjects were intermediate and high-risk patients unresponsive to current treatments. Main exclusion criteria were thrombocytopenia (PLT $<50 \times 10^{9} / \mathrm{L}$ ) and neutropenia $\left(\right.$ ANC $\left.<1000 \times 10^{9} / \mathrm{L}\right)$. The results available to date can be summarized in the following points. First, maximum tolerated dose (MTD) was $680 \mathrm{mg} /$ day and dose-limiting toxicity (DLT) was a reversible and asymptomatic increase in the serum amylase level. Dose chosen for a phase II/ III trial was $400 \mathrm{mg}$ or $500 \mathrm{mg}$ daily. Second, applying IWG-MRT criteria of response, $59 \%$ of patients achieved $\mathrm{CI}$ of spleen size by palpation at 6 months. The majority of patients with constitutional symptoms, fatigue, pruritus had a durable resolution without a measurable effect on cytokines. Across doses, leukocytosis and thrombocytosis were normalized at 12 months in $57 \%$ and $90 \%$ of patients. Third, no differences were reported in term of response rate according to $J A K 2$ (V617F) mutational status. Fourth, $39 \%$ of patients with more than $20 \%$ JAK2 (V617F) allele burden at enrollment had a reduction of mutation load exceeding $50 \%$ at 12 months. Fifth, grade 3 to 4 hematologic adverse events included anemia (occurring in $35 \%$ of 37 patients who were not RBC transfusion dependent at baseline), thrombocytopenia (24\%) and neutropenia (10\%). At doses ranging between $240 \mathrm{mg}$ and $520 \mathrm{mg}$, 2 of 5 (40\%) RBC transfusion-independent patients became RBC transfusion-dependent and 2 of 9 (22\%) had grade $3 / 4$ thrombocytopenia. The main nonhematologic adverse events included all grades nausea $(69 \%)$, diarrhea (64\%) vomiting (58\%), all self-limited and controlled by symptomatic treatments. Asymptomatic increase of lipase, AST, ALT, creatinine have been reported in roughly one quarter of patients.

\section{CONCLUSION}

The discovery of new oncogenetic mutations in MPN has enriched our knowledge in these diseases resulting in the refinement of diagnostic criteria and in potential advantages in prognostication. JAK2 inhibitors can be beneficial to patients with improvement of spleen size and constitutional symptoms. For the time being, these are the most relevant conclusions on these new small molecules with anti-JAK2 properties and any other deduction seems premature. 


\section{ACKNOWLEDGEMENTS}

This work was supported by grants from AIL (Associazione Italiana Leucemie, Linfomi e Mieloma), Varese Onlus, Italy

\section{REFERENCES}

1. Tefferi A, Vardiman JW: Classification and diagnosis of myeloproliferative neoplasms: the 2008 World Health Organization criteria and point-of-care diagnostic algorithms. Leukemia 2008, 22(1):14-22.

2. Passamonti F, Rumi E, Arcaini L, Boveri E, Elena C, Pietra D, Boggi S, Astori C, Bernasconi P, Varettoni M et al: Prognostic factors for thrombosis, myelofibrosis, and leukemia in essential thrombocythemia: a study of 605 patients. Haematologica 2008, 93(11):1645-1651.

3. Campbell PJ, Scott LM, Buck G, Wheatley K, East CL, Marsden JT, Duffy A, Boyd EM, Bench AJ, Scott MA et al: Definition of subtypes of essential thrombocythaemia and relation to polycythaemia vera based on JAK2 V617F mutation status: a prospective study. Lancet 2005, 366(9501):1945-1953.

4. PassamontiF, RumiE, Pungolino E, MalabarbaL, Bertazzoni P, Valentini M, Orlandi E, Arcaini L, Brusamolino E, Pascutto $\mathrm{C}$ et al: Life expectancy and prognostic factors for survival in patients with polycythemia vera and essential thrombocythemia. Am J Med 2004, 117(10):755-761.

5. Passamonti F, Rumi E, Caramella M, Elena C, Arcaini L, Boveri E, Del Curto C, Pietra D, Vanelli L, Bernasconi $\mathrm{P}$ et al: A dynamic prognostic model to predict survival in post-polycythemia vera myelofibrosis. Blood 2008, 111(7):3383-3387.

6. Passamonti F, Rumi E, Arcaini L, Castagnola C, Lunghi M, Bernasconi P, Giovanni Della Porta M, Columbo N, Pascutto C, Cazzola M et al: Leukemic transformation of polycythemia vera: a single center study of 23 patients. Cancer 2005, 104(5):1032-1036.

7. Beer PA, Delhommeau F, LeCouedic JP, Dawson MA, Chen E, Bareford D, Kusec R, McMullin MF, Harrison CN, Vannucchi AM et al: Two routes to leukemic transformation after a JAK2 mutation-positive myeloproliferative neoplasm. Blood 2010, 115(14):2891-2900.

8. Passamonti F, Rumi E, Pietra D, Elena C, Boveri E, Arcaini L, Roncoroni E, Astori C, Merli M, Boggi S et al: A prospective study of 338 patients with polycythemia vera: the impact of JAK2 (V617F) allele burden and leukocytosis on fibrotic or leukemic disease transformation and vascular complications. Leukemia 2010.

9. Gangat N, Wolanskyj AP, McClure RF, Li CY, Schwager $\mathrm{S}, \mathrm{Wu} \mathrm{W}$, Tefferi A: Risk stratification for survival and leukemic transformation in essential thrombocythemia: a single institutional study of 605 patients. Leukemia 2007, 21(2):270-276.
10. Gangat N, Strand J, Li CY, Wu W, Pardanani A, Tefferi A: Leucocytosis in polycythaemia vera predicts both inferior survival and leukaemic transformation. Br J Haematol 2007, 138(3):354-358.

11. Kralovics R, Passamonti F, Buser AS, Teo SS, Tiedt R, Passweg JR, Tichelli A, Cazzola M, Skoda RC: A gain-offunction mutation of JAK2 in myeloproliferative disorders. N Engl J Med 2005, 352(17):1779-1790.

12. Shi L, Wang S, Zangari M, Xu H, Cao TM, Xu C, Wu Y, Xiao F, Liu Y, Yang Y et al: Over-expression of CKS1B activates both MEK/ERK and JAK/STAT3 signaling pathways and promotes myeloma cell drug-resistance. Oncotarget 2010, 1(1):22-33.

13. Passamonti F, Rumi E, Pietra D, Della Porta MG, Boveri E, Pascutto C, Vanelli L, Arcaini L, Burcheri S, Malcovati L et al: Relation between JAK2 (V617F) mutation status, granulocyte activation, and constitutive mobilization of CD34+ cells into peripheral blood in myeloproliferative disorders. Blood 2006, 107(9):3676-3682.

14. Zaleskas VM, Krause DS, Lazarides K, Patel N, Hu Y, Li S, Van Etten RA: Molecular pathogenesis and therapy of polycythemia induced in mice by JAK2 V617F. PLoS ONE 2006, 1:e18.

15. Tiedt R, Hao-Shen H, Sobas MA, Looser R, Dirnhofer S, Schwaller J, Skoda RC: Ratio of mutant JAK2-V617F to wild-type Jak2 determines the MPD phenotypes in transgenic mice. Blood 2008, 111(8):3931-3940.

16. Chen E, Beer PA, Godfrey AL, Ortmann CA, Li J, CostaPereira AP, Ingle CE, Dermitzakis ET, Campbell PJ, Green AR: Distinct clinical phenotypes associated with JAK2V617F reflect differential STAT1 signaling. Cancer Cell 2010, 18(5):524-535.

17. Scott LM, Tong W, Levine RL, Scott MA, Beer PA, Stratton MR, Futreal PA, Erber WN, McMullin MF, Harrison CN et al: JAK2 exon 12 mutations in polycythemia vera and idiopathic erythrocytosis. N Engl J Med 2007, 356(5):459468.

18. Passamonti F, Elena C, Schnittger S, Skoda RC, Green AR, Girodon F, Kiladjian JJ, McMullin MF, Ruggeri $\mathrm{M}$, Besses $\mathrm{C}$ et al: Molecular and clinical features of the myeloproliferative neoplasm associated with JAK2 exon 12 mutations. Blood 2011, 117(10):2813-2816.

19. Pikman Y, Lee BH, Mercher T, McDowell E, Ebert BL, Gozo M, Cuker A, Wernig G, Moore S, Galinsky I et al: MPLW515L Is a Novel Somatic Activating Mutation in Myelofibrosis with Myeloid Metaplasia. PLoS Med 2006, 3(7):e270.

20. Pardanani AD, Levine RL, Lasho T, Pikman Y, Mesa RA, Wadleigh M, Steensma DP, Elliott MA, Wolanskyj AP, Hogan WJ et al: MPL515 mutations in myeloproliferative and other myeloid disorders: a study of 1182 patients. Blood 2006, 108(10):3472-3476.

21. Vannucchi AM, Antonioli E, Guglielmelli P, Pancrazzi A, Guerini V, Barosi G, Ruggeri M, Specchia G, Lo-Coco F, 
Delaini $\mathrm{F}$ et al: Characteristics and clinical correlates of MPL $515 \mathrm{~W}>\mathrm{L} / \mathrm{K}$ mutation in essential thrombocythemia. Blood 2008, 112(3):844-847.

22. Tefferi A, Pardanani A, Lim KH, Abdel-Wahab O, Lasho TL, Patel J, Gangat N, Finke CM, Schwager S, Mullally A et al: TET2 mutations and their clinical correlates in polycythemia vera, essential thrombocythemia and myelofibrosis. Leukemia 2009, 23(5):905-911.

23. Delhommeau F, Dupont S, Della Valle V, James C, Trannoy S, Masse A, Kosmider O, Le Couedic JP, Robert F, Alberdi A et al: Mutation in TET2 in myeloid cancers. N Engl J Med 2009, 360(22):2289-2301.

24. Schaub FX, Looser R, Li S, Hao-Shen H, Lehmann T, Tichelli A, Skoda RC: Clonal analysis of TET2 and JAK2 mutations suggests that TET2 can be a late event in the progression of myeloproliferative neoplasms. Blood 2010, 115(10):2003-2007.

25. Gery S, Cao Q, Gueller S, Xing H, Tefferi A, Koeffler HP: Lnk inhibits myeloproliferative disorder-associated JAK2 mutant, JAK2V617F. J Leukoc Biol 2009, 85(6):957-965.

26. Tong W, Zhang J, Lodish HF: Lnk inhibits erythropoiesis and Epo-dependent JAK2 activation and downstream signaling pathways. Blood 2005, 105(12):4604-4612.

27. Pardanani A, Lasho T, Finke C, Oh ST, Gotlib J, Tefferi A: LNK mutation studies in blast-phase myeloproliferative neoplasms, and in chronic-phase disease with TET2, IDH, JAK2 or MPL mutations. Leukemia 2010.

28. Lasho TL, Pardanani A, Tefferi A: LNK mutations in JAK2 mutation-negative erythrocytosis. N Engl J Med 2010, 363(12):1189-1190.

29. Ernst T, Chase AJ, Score J, Hidalgo-Curtis CE, Bryant C, Jones AV, Waghorn K, Zoi K, Ross FM, Reiter A et al: Inactivating mutations of the histone methyltransferase gene EZH2 in myeloid disorders. Nat Genet 2010, 42(8):722-726.

30. Reynolds RM, Browning GG, Nawroz I, Campbell IW: Von Recklinghausen's neurofibromatosis: neurofibromatosis type 1. Lancet 2003, 361(9368):1552-1554.

31. Stegelmann F, Bullinger L, Griesshammer M, Holzmann K, Habdank M, Kuhn S, Maile C, Schauer S, Dohner H, Dohner $\mathrm{K}$ : High-resolution single-nucleotide polymorphism arrayprofiling in myeloproliferative neoplasms identifies novel genomic aberrations. Haematologica 2010, 95(4):666-669.

32. Cazzola M: IDH1 and IDH2 mutations in myeloid neoplasms--novel paradigms and clinical implications. Haematologica 2010, 95(10):1623-1627.

33. Green A, Beer P: Somatic mutations of IDH1 and IDH2 in the leukemic transformation of myeloproliferative neoplasms. N Engl J Med 2010, 362(4):369-370.

34. Tefferi A, Lasho TL, Abdel-Wahab O, Guglielmelli P, Patel J, Caramazza D, Pieri L, Finke CM, Kilpivaara O, Wadleigh $\mathrm{M}$ et al: IDH1 and IDH2 mutation studies in 1473 patients with chronic-, fibrotic- or blast-phase essential thrombocythemia, polycythemia vera or myelofibrosis.
Leukemia 2010, 24(7):1302-1309.

35. Carbuccia N, Murati A, Trouplin V, Brecqueville M, Adelaide J, Rey J, Vainchenker W, Bernard OA, Chaffanet M, Vey $\mathrm{N}$ et al: Mutations of ASXL1 gene in myeloproliferative neoplasms. Leukemia 2009, 23(11):2183-2186.

36. Makishima H, Cazzolli H, Szpurka H, Dunbar A, Tiu R, Huh J, Muramatsu H, O'Keefe C, Hsi E, Paquette RL et al: Mutations of e3 ubiquitin ligase cbl family members constitute a novel common pathogenic lesion in myeloid malignancies. J Clin Oncol 2009, 27(36):6109-6116.

37. Naramura M, Nadeau S, Mohapatra B, Ahmad G, Mukhopadhyay C, Sattler M, Raja SM, Natarajan A, Band $\mathrm{V}$, Band $\mathrm{H}$ : Mutant $\mathrm{Cbl}$ proteins as oncogenic drivers in myeloproliferative disorders. Oncotarget 2011, 2(3):245250 .

38. Grand FH, Hidalgo-Curtis CE, Ernst T, Zoi K, Zoi C, McGuire C, Kreil S, Jones A, Score J, Metzgeroth G et al: Frequent $\mathrm{CBL}$ mutations associated with $11 \mathrm{q}$ acquired uniparental disomy in myeloproliferative neoplasms. Blood 2009, 113(24):6182-6192.

39. Jager R, Gisslinger H, Passamonti F, Rumi E, Berg T, Gisslinger B, Pietra D, Harutyunyan A, Klampfl T, Olcaydu D et al: Deletions of the transcription factor Ikaros in myeloproliferative neoplasms. Leukemia 2010, 24(7):1290-1298.

40. Verstovsek S, Kantarjian H, Mesa RA, Pardanani AD, Cortes-Franco J, Thomas DA, Estrov Z, Fridman JS, Bradley EC, Erickson-Viitanen $S$ et al: Safety and efficacy of INCB018424, a JAK1 and JAK2 inhibitor, in myelofibrosis. N Engl J Med 2010, 363(12):1117-1127.

41. Pardanani A, Gotlib JR, Jamieson C, Cortes JE, Talpaz M, Stone RM, Silverman MH, Gilliland DG, Shorr J, Tefferi A: Safety and efficacy of TG101348, a selective JAK2 inhibitor, in myelofibrosis. J Clin Oncol 2011, 29(7):789796.

42. Mullally A, Lane SW, Ball B, Megerdichian C, Okabe R, Al-Shahrour F, Paktinat M, Haydu JE, Housman E, Lord AM et al: Physiological Jak2V617F expression causes a lethal myeloproliferative neoplasm with differential effects on hematopoietic stem and progenitor cells. Cancer Cell 2010, 17(6):584-596. 